\title{
Intensification of drag reduction effect by simultaneous addition of surfactant and high molecular polymer into the solvent
}

\author{
Zbigniew Matras, Bartosz Kopiczak* \\ Division of Fluid Mechanics, Institute of Thermal and Process Engineering, Cracow University of Technology, \\ Al. Jana Pawla II 37, Cracow 31-864, Poland
}

\section{A R T I C L E I N F O}

\section{Article history:}

Received 11 August 2014

Received in revised form 3 February

2015

Accepted 9 February 2015

Available online 16 February 2015

Keywords:

Drag reduction

Polymer

Surfactant

Macromolecule

Micelle

Aggregate

\begin{abstract}
A B S T R A C T
The paper presents the analysis of the possibilities of intensification of drag reduction effect (DR) by simultaneous addition of non-ionic high molecular polymer - poly(ethylene oxide) and the cationic surfactant - cetyltrimetyl ammonium bromide into the solvent. Salt sodium salicylate was applied as a counter-ion. The analyzed solutions were compared with their pure polymer or micellar equivalents.

Clear existence of three drag reduction zones was observed: stable transitional zone, unstable transitional zone and in particular the third turbulent drag reduction zone. The dominant factor which influenced $D R$ in the transitional zone was the addition of $\mathrm{CTAB}+\mathrm{NaSal}$. In the third zone, the addition of PEO had decisive influence on the DR intensity. The increase of PEO concentration enhanced DR in this zone.

The influence of pipes diameter on the DR was investigated. The increase of pipe diameter caused clear extension of the stable transitional zone. In the third zone DR increased while decreasing pipe diameter.

Analyses showed that the value of the $n$ flow index was not an important factor in the DR.

The results indicate that polymer-micellar solutions combine and intensify positive features of their pure polymer and micellar equivalents, providing efficient DR in a wider range of the Reynolds numbers.

(C) 2015 The Institution of Chemical Engineers. Published by Elsevier B.V. All rights reserved.
\end{abstract}

\section{Introduction}

Abnormal drag reduction in turbulent flow by addition of surfactants and polymers is the phenomenon intensely studied and described in the literature (Matras, 1984; Borostow, 2008; White and Mungal, 2008; Tamano et al., 2010; Hadri et al., 2011; Wang et al., 2011; Shu-Peng, 2012). The effect of abnormal drag reduction allows significantly for the increase of the flow rate without the necessity of increasing power demand, or vice versa - reducing power demand while maintaining a constant flow rate. Therefore, it provides potentially high possibilities of this effect application in different industrial sectors, particularly in oil industry, heat engineering, firefighting, transport of slurries, sludge and brines (Motier et al., 1996; Figueredo and Sabadini, 2003; Dujmovich and Gallegos, 2005; White and Mungal, 2008; Wang et al., 2011). The causes of the drag reduction effect have been associated with the existence of new internal solution structure which formulates when special additives are mixed with solvent. The addition of high molecular polymer agents into the solvent results in macromolecule structure formation (Matras, 1984; White and Mungal, 2008). In case of application of surfactants as drag reducing additives, formation of micelles is observed (Tamano et al., 2010; Hadri et al., 2011; Wang et al., 2011). At standstill,

\footnotetext{
* Corresponding author. Tel.: +48 510065761; fax: +48 126485771.

E-mail addresses: zmatras@mech.pk.edu.pl (Z. Matras), bkopiczak@mech.pk.edu.pl, bartek.kopiczak@gmail.com (B. Kopiczak). http://dx.doi.org/10.1016/j.cherd.2015.02.006 0263-8762/@ 2015 The Institution of Chemical Engineers. Published by Elsevier B.V. All rights reserved.
} 


\begin{tabular}{|c|c|}
\hline \multicolumn{2}{|c|}{ Nomenclature } \\
\hline$c_{f}$ & fanning friction coefficient [Eq. (3)] \\
\hline$c_{\mathrm{fS}}$ & $\begin{array}{l}\text { Fanning friction coefficient referenced to the } \\
\text { pure solvent }\end{array}$ \\
\hline$c_{\mathrm{fM}}$ & modified, Fanning friction coefficient \\
\hline$d$ & pipe diameter $[\mathrm{m}]$ \\
\hline K & fluid consistency constant $\left[\mathrm{kg} \mathrm{s}^{n-2} / \mathrm{m}\right]$ \\
\hline L & length of pipe measurement distance [m] \\
\hline$n$ & flow behaviour index of power law fluid model \\
\hline$\Delta P$ & pressure loss [Pa] \\
\hline $\operatorname{Re}_{\mathrm{M}}$ & modified Reynolds number \\
\hline $\operatorname{Re}_{\mathrm{S}}$ & $\begin{array}{l}\text { Reynolds number referenced to the pure sol- } \\
\text { vent [Eq. (2)] }\end{array}$ \\
\hline$v_{\mathrm{m}}$ & mean velocity of pipe flow $[\mathrm{m} / \mathrm{s}]$ \\
\hline$\rho$ & solution density $\left[\mathrm{kg} / \mathrm{m}^{3}\right]$ \\
\hline$\rho_{\mathrm{S}}$ & solvent density $\left[\mathrm{kg} / \mathrm{m}^{3}\right]$ \\
\hline$\eta$ & solution apparent viscosity $[\mathrm{kg} / \mathrm{ms}]$ \\
\hline$\eta_{\mathrm{S}}$ & solvent dynamic viscosity [kg/ms] \\
\hline
\end{tabular}

when fluid is at rest, described structures are chaotic. In fluid motion state, where fluid is under shear stress influence, both macromolecules and micelles start to arrange in characteristic orientation, in accordance with the principle of the minimum resistance. In order to improve micellization process effectiveness, small amounts of electrolytes are added into the solution, e.g. salts sodium salicylate or sodium bromide. The effect of drag reduction of flow by high molecular polymer or surfactants has also some limitations which come from the properties of additives. The main disadvantage of high molecular polymers is their susceptibility to mechanical and thermal degradation (Kim et al., 2000; White and Mungal, 2008; Mohsenipour and Pal, 2013a). In case of surfactant solutions, it is a certain critical Reynolds number exceeding of which results in the loss of micelles orientation and the collapse of the DR effect (Wang et al., 2011). The addition of surfactant to polymer solution effectively reduces polymer degradation process, especially when the flow temperature of the solution is high (Kim et al., 2000; Mohsenipour and Pal, 2013a).

The phenomenon of the fluid flow drag reduction by simultaneous addition of the high molecular polymer and the surfactant with salt additives into the solvent is still a relatively new and poorly recognized issue. Mainly internal structure formation and chemical reaction processes in polymer-micellar solutions are highlighted in a few published works related to this subject (DaRocha et al., 1999; Hou et al., 1999; Suksamranchit et al., 2006; Kim et al., 2011). The first attempts of drag reduction effect experimental examination have been performed, confirming that the simultaneous addition of polymer and surfactant with salt into the solvent, combine positive features of their purely polymer and micellar analogues providing additional extension of drag reduction zones (Matras et al., 2008; Malcher and Gzyl-Malcher, 2012; Mohsenipour and Pal, 2013; Mohsenipour and Pal, 2013b; Mohsenipour et al., 2013). The pipeline drag reduction measurements reveal a considerable synergistic effect, that is, the mixed polymer-surfactant aggregates produce a significantly higher drag reduction, when compared with their pure polymer or pure surfactant equivalents. However, the synergistic effect in a mixed systems is stronger at low nonionic polymer concentrations and high cationic surfactant concentrations (Mohsenipour and Pal, 2013).
Nevertheless the researches indicate that this new effect requires a comprehensive experimental study to gain a deeper knowledge of this phenomenon (Matras et al., 2008; Malcher and Gzyl-Malcher, 2012; Mohsenipour and Pal, 2013b; Mohsenipour et al., 2013).

The aim of this work is experimental confirmation of the thesis that simultaneous addition of surfactants and high molecular polymer additives into a solvent causes intensification of the drag reduction effect and significant extension of the drag reduction zones, in comparison with the drag reduction effect obtained by application of the pure polymer or pure surfactant additives.

\section{Characteristic of polymer-micellar solution internal structure}

The existence of the polymer in a surfactant solution enhances the ability of surfactant to form micelle structures at much lower concentration, when compared with the critical micelle concentration (CMC) (Matras et al., 2008; Mohsenipour and Pal, 2013b). The addition of small amount of salt (e.g. $\mathrm{NaSal}$ ) to the high molecular polymer and surfactant solution causes the increase in the size of micelles. It also increases the amount of micelles linked to the polymer chain. The concentration at which the initiation of micelle formations occurs in the presence of polymer macromolecules is called the critical aggregation concentration (CAC). The newly formed polymermicelle macromolecules are called aggregates (DaRocha et al., 1999).

Upon the experimental study of polymer-micellar aqueous solutions (DaRocha et al., 1999), mechanism of the aggregates formation process can be illustrated in Fig. 1. The structure of polymer chain is indicated with solid lines in the figure. Remaining elements correspond to particles of the surfactant in the solvent. Initially polymer and surfactant molecules occur in the solution independently. The situation significantly changes when a small amount of salt is added into the solution. According to (DaRocha et al., 1999; Matras et al., 2008), it causes surfactant micelles size growth, as well as linking of the polymer with surfactant micelles and forming aggregates by polymer wrapping around the rod micelles. The consequence of this is an increase in the viscosity of the solution.

\section{Materials and measurements}

The rotational and the capillary rheometers, that have been in use so far, give the ability for effective rheological identification of liquid in the laminar range. Unfortunately abnormal effects can occur only during the flow of rheologically complex polymer and micellar solution in the turbulent range of flow, and especially in the extremely fascinating but difficult for the mathematical description transitional zone. Thus, these effects cannot be interpreted with the use of aforementioned types of rheometers.

Having analyzed the level of difficulty of planned experimental tests and taking into account the type of physical quantities to be measured, the experiment was performed using a pipe-flow apparatus of our own design. The device allows to conduct a comprehensive identification of rheological characteristics of the examined liquid in laboratory conditions.

The versatility of the described pipe-flow apparatus allows to assign not only classical experimental flow curves in the 


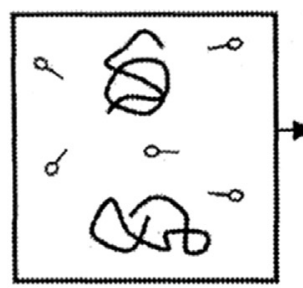

a)

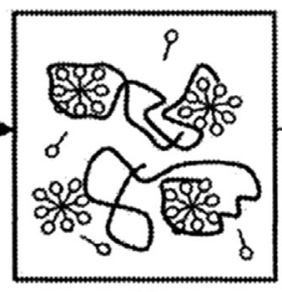

b)

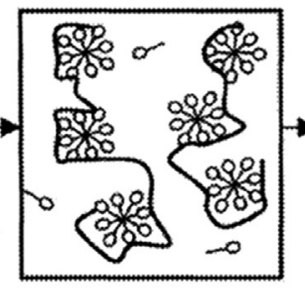

c)

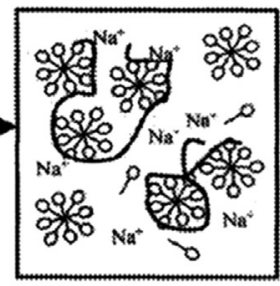

d)

Fig. 1 - Mechanism of the polymer-micelle aggregates formation (DaRocha et al., 1999). (a) Concentration of both polymer and surfactant additives is too low to induce interaction between additives molecules. (b) Increase in concentration leads to micelles and aggregates structure formation. (c) Polymer saturation point (PSP) - maximum viscosity value of mixture is reached. (d) Further increase in solution concentration leads to the phenomenon of electrostatic screen insulating separate micelles.

laminar range of flow, but also to examine and interpret properly the flow characteristics of fluids which behave differently when compared with purely viscous non-Newtonian fluids in the turbulent flow region. That applies primarily to the solutions of polymers and surfactants, which are the subject of research in this work, as well as to the fluids which can be considered on the border between the physical continuum and multi-phase system, e.g. rheostable (purely viscous) or viscoelastic suspensions. A schematic diagram of the pipe-flow apparatus is illustrated in Fig. 2.

The basic elements of the device are straight capillaries and pipes with circular cross-section (1). Each pipe, installed in pipe-flow apparatus, has two small diameters (1[mm]) static pressure holes, spotted in the pipe wall at the distance of $L=2[\mathrm{~m}]$ from each other. In case of capillaries the distance between the static pressure holes is equal to $L=1[\mathrm{~m}]$. They are used for the measurement of fluid flow pressure loss at pipe distance L. Static pressure holes were spotted at distances $L_{\text {inl }}=L_{\text {out }} \approx 150 d$ from the pipe inlet and outlet. This ensures stable flow conditions and eliminates the influence of the socalled "entrance effect."

The fluid flow in the pipe-flow apparatus is forced by two hermetic multistage rotodynamic pumps (6), which suck in the fluid from one of the tanks (9) and pump it then into one of the eight horizontal pipes of different diameters (1). After passing through one of the three electromagnetic flowmeters with different measurement ranges (3) the fluid returns to the storage tank. The measurements of the pressure losses were performed using PD1 or PDF differential pressure drop sensors (2), which were connected to pipes and capillaries with flexible pressure conduits. Differential pressure drop sensor ranges were selected in such a way as to achieve a high accuracy of pressure losses in various flow conditions, mainly dependent on the viscosity of the examined fluid and the flow rate value.

For the current temperature control (possibility of maintaining a constant temperature in the measuring system was provided) a resistive temperature sensor (12) was placed in the fluid supply pipe.

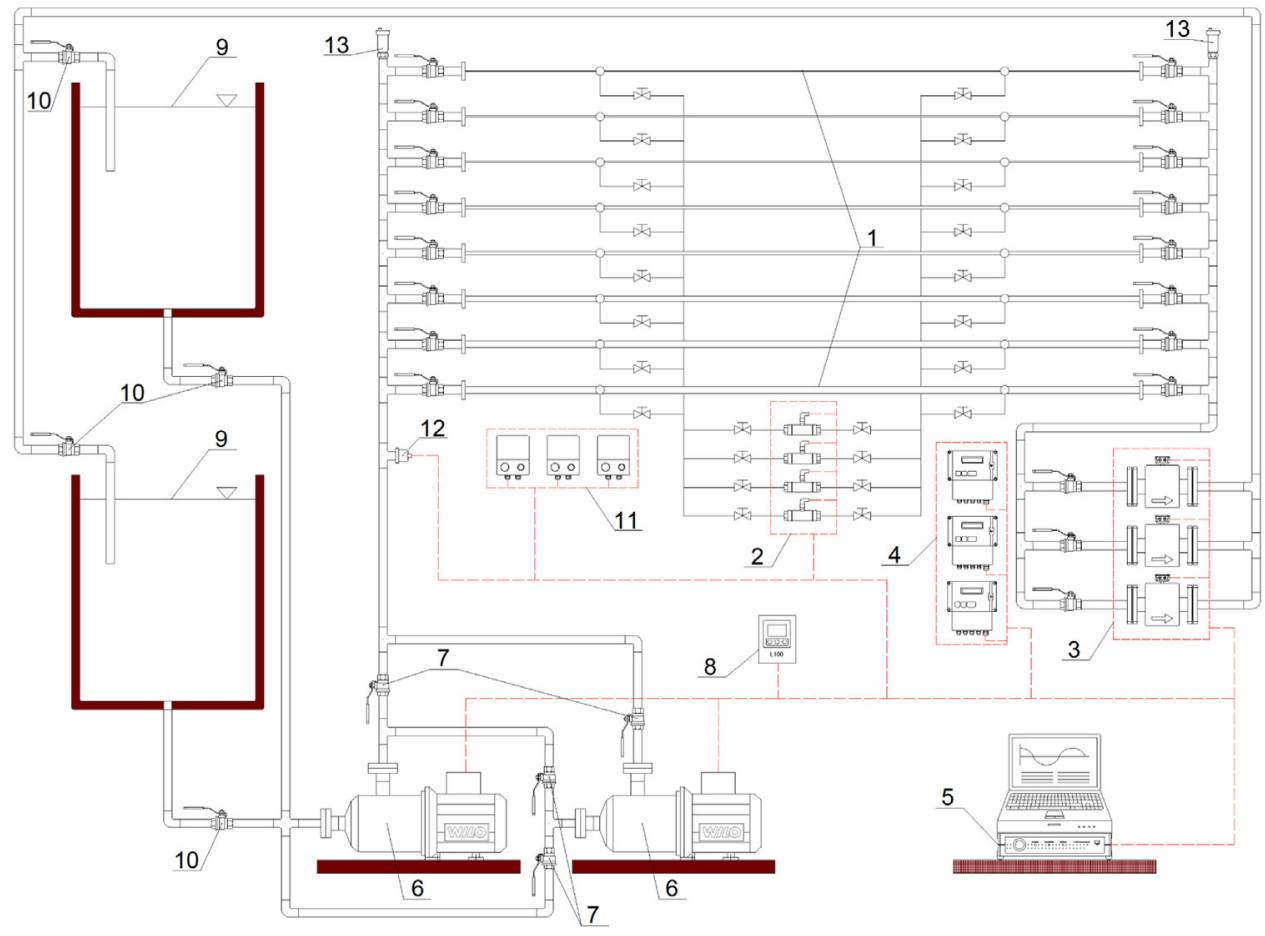

Fig. 2 - Diagram of the multifunction pipe-flow apparatus. 1 - straight capillaries and pipes with circular cross-section; 2 differential pressure drop sensors PD1 and PDF, 3 - electromagnetic flowmeters; 4 - flowmeter controllers; 5 - data acquisition system SPIDER; 6 - multistage rotodynamic pumps with triple-phase electrical engine; 7 - valves controlling pumps; 8 - microprocessor frequency converter L100; 9 - tanks; 10 - valves controlling tanks work; 11 - amplifiers WP-01A; 12 - temperature sensors PT 100, 13 - vent valves 
Table 1 - Summary of the analyzed solutions and their designated rheological constants.

\begin{tabular}{llll} 
Solution designation & \multicolumn{1}{c}{ Solutions composition } & $\mathrm{K}\left[\mathrm{Pa} \mathrm{s} \mathrm{s}^{n}\right]$ & $n$ \\
\hline No. 1 & $30 \mathrm{ppm}$ PEO & 0.0011 & 0.970 \\
No. 2 & $100 \mathrm{ppm}$ NaSal; 200 ppm CTAB & 0.0030 & 0.869 \\
No. 3 & $200 \mathrm{ppm}$ NaSal; 400 ppm CTAB & 0.0083 & 0.748 \\
No. 4 & $30 \mathrm{ppm}$ PEO; 100 ppm NaSal; 200 ppm CTAB & 0.0048 & 0.772 \\
No. 5 & $30 \mathrm{ppm}$ PEO; 200 ppm NaSal; 400 ppm CTAB & 0.0134 & 0.631 \\
No. 6 & $60 \mathrm{ppm}$ PEO; 100 ppm NaSal; 200 ppm CTAB & 0.0030 & 0.868 \\
No. 7 & $60 \mathrm{ppm}$ PEO; 200 ppm NaSal; 400 ppm CTAB & 0.0058 & 0.800 \\
\hline
\end{tabular}

Thanks to the appropriate valve (7) control, the pumps can work in series or parallel arrangement, depending on the required flow rate or pressure loss value. This allows to obtain a wide range of Reynolds number reaching the value of $3 \times 10^{5}$ for the measurement system pressure value up to $10[\mathrm{bar}]$, without the loss of fluid continuity (no foaming of the solution or air bubbles). Each pump is driven by a triple-phase electrical engine.

A microprocessor frequency converter (8) was used to control the pump frequency and consequently volumetric flow rate. The main element supporting the action of the pipeflow apparatus is a multi-channel data acquisition system SPIDER 8 (Hottinger Baldwin Messtechnik), arranged to measure the electrical signals from the different sensors (tension, force, pressure, displacement, acceleration and temperature sensors). A data acquisition system is connected to the PC Notebook that receives the measurement data that is recorded and processed.

In order to avoid the unnecessary vibration, the whole measurement system is installed on a special carrying ramp and rubber pads. Similarly, the whole pipeline was secured with shock-absorbing flexible rubber connectors. Additionally, large volume tanks $\left(1\left[\mathrm{~m}^{3}\right]\right)$ were used to eliminate the effect of foaming of micellar and polymer-micellar solutions and to minimize the influence of the unavoidable degradation of the polymer-micellar aggregates or macromolecular structures on measurement results, During the preparation of the polymer-surfactant solutions, $\mathrm{pH}$ of chosen drag reducing additives should be particularly considered. Incorrect selection of $\mathrm{pH}$ may result in an undesired chemical reaction.

Anionic surfactants cannot be used while aqueous solutions of certain polymers can have an acidic reaction. Cationic and anionic surfactants can be combined with non-ionic polymer solutions.

After a preliminary study, the following drag reducers were used for the experimental analysis:

- non-ionic polymer with a high molecular weight $\mathrm{M}_{\mathrm{V}}=8 \cdot 10^{6}$ - poly(ethylene oxide) - $\left[\mathrm{CH}_{2} \mathrm{CH}_{2} \mathrm{O}\right]_{n}$ (PEO);

- cationic surfactant - cetyltrimetyl ammonium bromide $\left[\mathrm{CH}_{3}\left(\mathrm{CH}_{2}\right) i_{5} \mathrm{~N}\left(\mathrm{CH}_{3}\right)_{3}\right]+\mathrm{Br} \sim(\mathrm{CTAB})$.

In order to lower the CAC value, salt sodium salicylate $\mathrm{C}_{7} \mathrm{H}_{5} \mathrm{NaO}_{3}$ (NaSal) was used. The mass fraction of the salt in a solvent was always twice lower than the mass fraction of the surfactant. Distilled water was used as the solvent. After addition of the appropriate drag reducers into the solvent, solutions were mixed gently so as not to cause mechanical degradation of polymer chains. Before taking measurements, mixtures were left at rest for $24 \mathrm{~h}$.

In order to conduct a comparative analysis of the drag reduction efficiency caused by a simultaneous addition of surfactant and high molecular polymer additives into the solvent in contrast to the drag reduction effect obtained by the addition of pure polymer or pure surfactant agents, 7 solution compositions and concentrations of additives were investigated. The designation and the composition of analyzed mixtures are presented in Table 1.

Adiabatic steady flows of homogenous solutions were examined in 8 different straight pipes having the diameters ranging between $1.8[\mathrm{~mm}]$ and $21[\mathrm{~mm}]$, in the temperature equal to $27^{\circ} \mathrm{C}$.

\section{Rheological characteristics and flow resistance measurements results}

In order to identify rheological characteristics of the analyzed solutions, experimental/pipe-flow curves were drawn for each of them in the form of functional relationship described by the equation:

$\tau_{w}=f(\Gamma)$

where: $\tau_{w}=d \Delta \mathrm{P} / 4 \mathrm{~L}$ is the shear stress at the pipe wall, $\Gamma=$ $8 v_{m} / d$ is the pipe shear rate (value of shear rate at the pipe wall).

Rheological characteristics of polymer-micellar solutions differ from the rheological characteristics of a pure solvent. The flow curves of all examined solutions can be described by Ostwald - de Waele power law fluid model in a wide range of shear rates.

Representative pipe flow curves and apparent viscosity vs. shear rate are illustrated in Figs. 3 and 4 respectively.

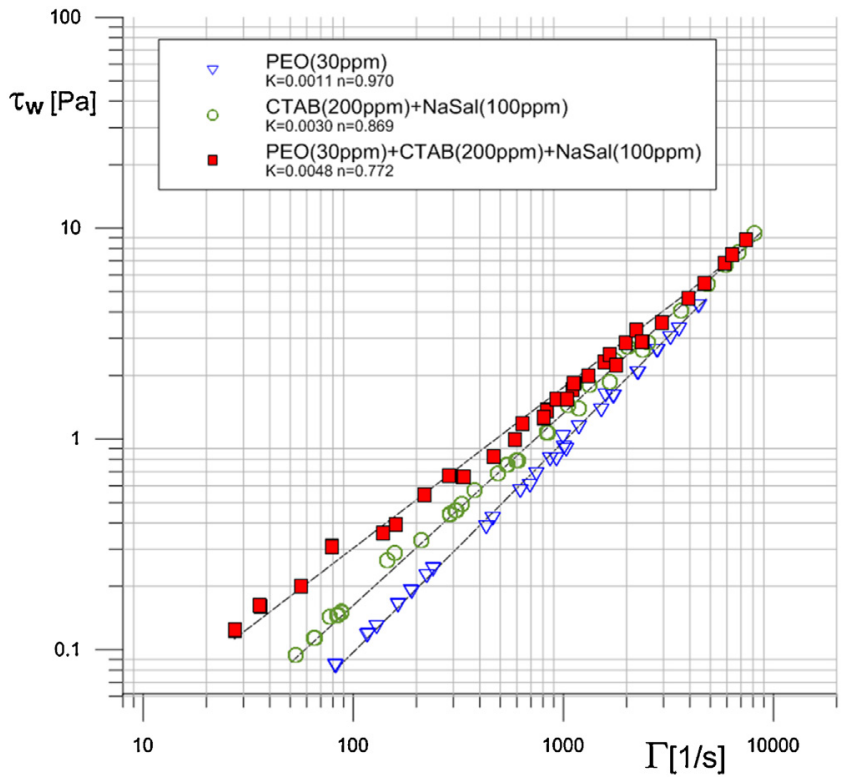

Fig. 3 - Representative experimental flow curves for polymer, surfactant and polymer-surfactant solutions. 


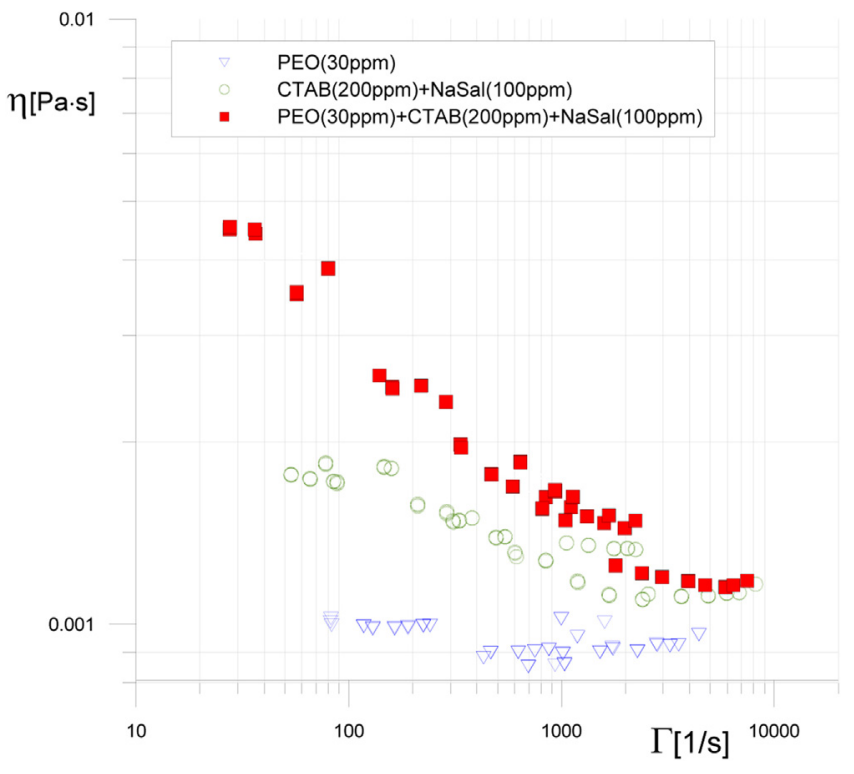

Fig. 4 - Apparent viscosity vs. shear rate curves for polymer, surfactant and polymer-surfactant solutions.

The values of rheological parameters: $K$ (fluid consistency constant) and $n$ (the flow behaviour index) for each analyzed solution are summarized in Table 1.

The mass fraction of individual additives, composing rheologically complex polymer-micellar solution affects the value of the $n$ flow index. This parameter characterizes nonNewtonian properties of a fluid. There is no way to predict a priori its value for a solution composed arbitrarily and having different mass frictions of particular drag reducers.

It was only observed that the increase of both CTAB and $\mathrm{NaSal}$ concentration in the examined solution having a constant polymer concentration, leads to the intensification of non-Newtonian properties of the fluid, i.e. to the increase of the value of fluid consistency constant $K$ and the decrease of the $n$ flow index.

The interpretation of experimental data and the assessment of the respective solution additives' influence on the increase or reduction of the flow resistance and the shape and location of resistance curves depends significantly on the adopted coordinate system in which these data are presented.

One of the methods used for estimation of the polymer or surfactant solution flow drag reduction is the analysis of flow resistance curves, presented in a classical system of dimensionless numbers $\left[\operatorname{Re}_{\mathrm{S}}, \mathrm{c}_{\mathrm{f}}\right]$, described by formulas (2) and (3):

$\operatorname{Re}_{\mathrm{S}}=\frac{v_{\mathrm{m}} \rho_{\mathrm{S}} d}{\eta_{\mathrm{S}}}$

$c_{f}=\frac{d \Delta P}{2 \rho v_{m}^{2} L}$

where $R_{S}$ is solvent viscosity based Reynolds number.

Additionally the experimental results of the flow resistance are presented in the form of the drag reduction coefficient DR defined as a function of the Reynolds number (2), and prescribed in percentage term:

$\mathrm{DR}=\left(1-\frac{\mathrm{c}_{\mathrm{f}}}{\mathrm{C}_{\mathrm{fS}}}\right) \cdot 100 \%$

The analysis of the flow resistance curves reveals that none of the analyzed flow ranges measurement points corresponds

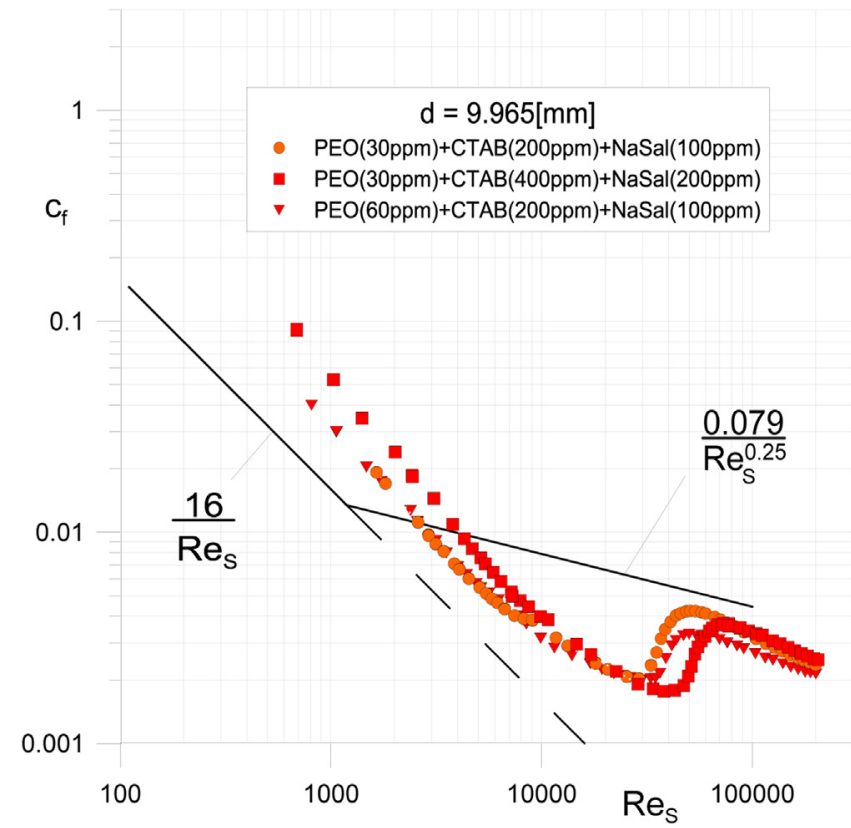

Fig. 5 - The flow resistance curves of polymer-surfactant water solutions, defined in the system of cardinal numbers (2) and (3).

to the theoretical functions which describe the Newtonian fluid flow - Fig. 5.

Qualitative analysis of the curves presented in such system of dimensionless numbers in Fig. 5 leads to ambiguous conclusions. This is result of the fact that the definition of Reynolds number $R_{S}$ does not take into account diversified non-Newtonian rheological properties of the compared solutions. Basing on the analysis of the curves presented in Fig. 5, it can be only concluded that, with a constant value of $R e_{S}$, the polymer or/and the surfactant with salt additives cause an increase of flow resistance in the laminar range of flow and a significant reduction of flow resistance in the turbulent range of flow. The increase in $c_{\mathrm{f}}$ value in Fig. 5 and the appearance of negative values of DR in the laminar range of flow in Fig. 6 results from the fact that the real apparent viscosity of all analyzed solutions is greater in comparison with viscosity

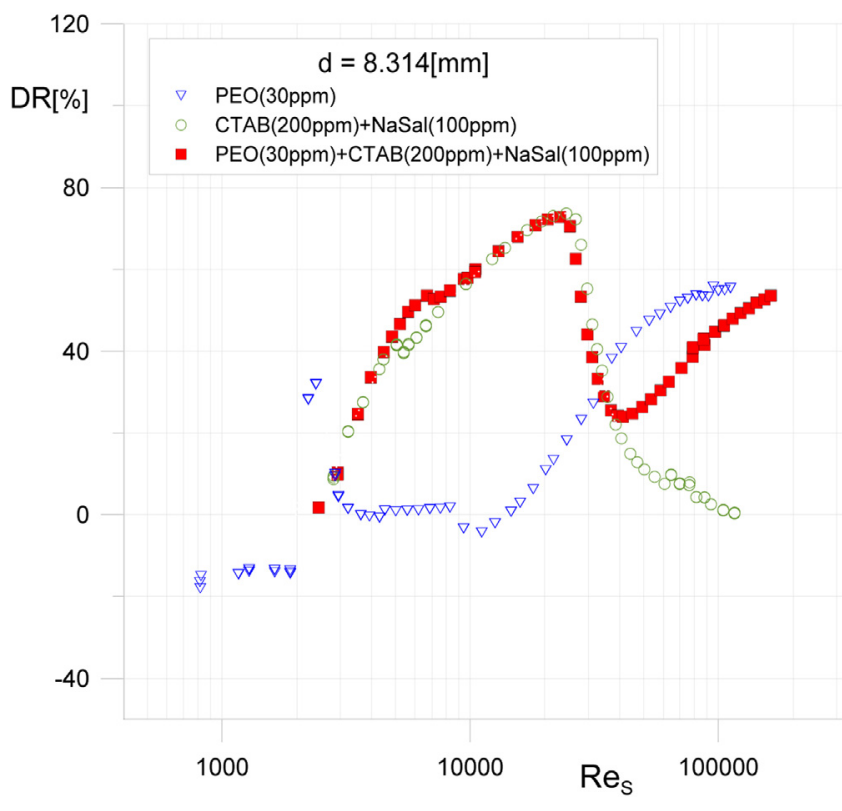

Fig. 6 - The drag reduction coefficient curves $D R=f\left(R e_{S}\right)$. 
of pure solvent (see Fig. 4) and is a decreasing function of the shear rate $\Gamma$. In the case of the polymer solution presented in Fig. 6, the apparent viscosity of the solution is greater than the viscosity of the solvent by approx. $15 \%$. The value of the critical Reynolds number, for which transition from the laminar flow to the turbulent flow is observed, takes various values depending on pipe diameters, the type and concentration of chemical additives introduced to the solvent.

Due to the difficulty in unambiguous determination of the critical value Reynolds number Res, the DR values presented in Fig. 6 are calculated in such way that it was assumed that $c_{\mathrm{fS}}=16 / \mathrm{Re}_{\mathrm{S}}$ in the range of Reynolds number $R e_{\mathrm{S}}<2100$, whereas the formula $c_{\mathrm{fS}}=0.079 / R e_{\mathrm{s}}^{-0.25}$ was used in the range of Reynolds number $\operatorname{Re}_{S} \geq 2100$. Therefore, a sharp increase of the DR value observed in the transition zone, particularly in the polymer solution (Fig. 6) does not reflect the actual degree of drag reduction in this range of flow. In case of the polymer solution flow, in the initial stage of the turbulent flow, no noticeable reduction of flow resistance is observed. Only after exceeding certain characteristic Reynolds number $\mathrm{Re}_{\mathrm{S}} \approx 1.5 \times 10^{4}$, the onset of the drag reduction effect occurs and the phenomenon increases with the increase in the value of Reynolds number. A similar increase in the reduction of the shear resistance in rotating disc apparatus for the turbulent flow range, induced with $\mathrm{PEO}$ additive, was observed in Kim et al. (2001).

In order to obtain a better interpretation of the effect that the simultaneous addition of the polymer and surfactant with salt has on drag reduction, comparing to adequate addition of pure polymer or pure surfactant with salt, can be achieved by presentation of the same measurement data in modified system of "pseudo-Newtonian" (Matras, 1984) dimensionless numbers $\left[R e_{\mathrm{M}}, c_{\mathrm{fM}}\right]$, and described by formulae (5) and (6):

$$
\begin{aligned}
& R e_{\mathrm{M}}=\frac{d^{n} v_{\mathrm{m}}^{2-n} \rho_{\mathrm{S}}}{K((3 n+1) / 4 n)^{n} 8^{n-1}}\left[\frac{2(n+1)}{3 n+1}\right]^{-2.5} \\
& c_{\mathrm{fM}}=\frac{d \Delta P}{2 \rho v_{\mathrm{m}}^{2} L}\left[\frac{2(n+1)}{3 n+1}\right]^{2.5}
\end{aligned}
$$

Obviously (Matras, 1984), in so defined dimensionless number system, the flow resistance curves of "pseudo-Newtonian" (purely viscous) non-Newtonian fluids are transformed to a single curve - in the whole range of the modified Reynolds number - identical to the classical Newtonian curve described in the laminar range by Fanning equation:

$c_{\mathrm{fM}}=\frac{16}{R e_{\mathrm{M}}}$

and in the turbulent flow by the Blasius formula:

$c_{\mathrm{fM}}=\frac{0.079}{\operatorname{Re}_{\mathrm{M}}^{0.25}}$

Additionally, the selection of such a coordinate system was dictated by the fact that it facilitated the identification and description of the characteristic drag reduction flow zones. That is why, among others, each deviation of the experimental flow resistance curve which indicates abnormal drag reduction from pseudorheostable Blasius curve (8), allows to identify the influence of specific additives (polymers or/and surfactants with salt) on the range of the analyzed drag reduction effect. Fig. 7 presents the comparison of flow resistance curves

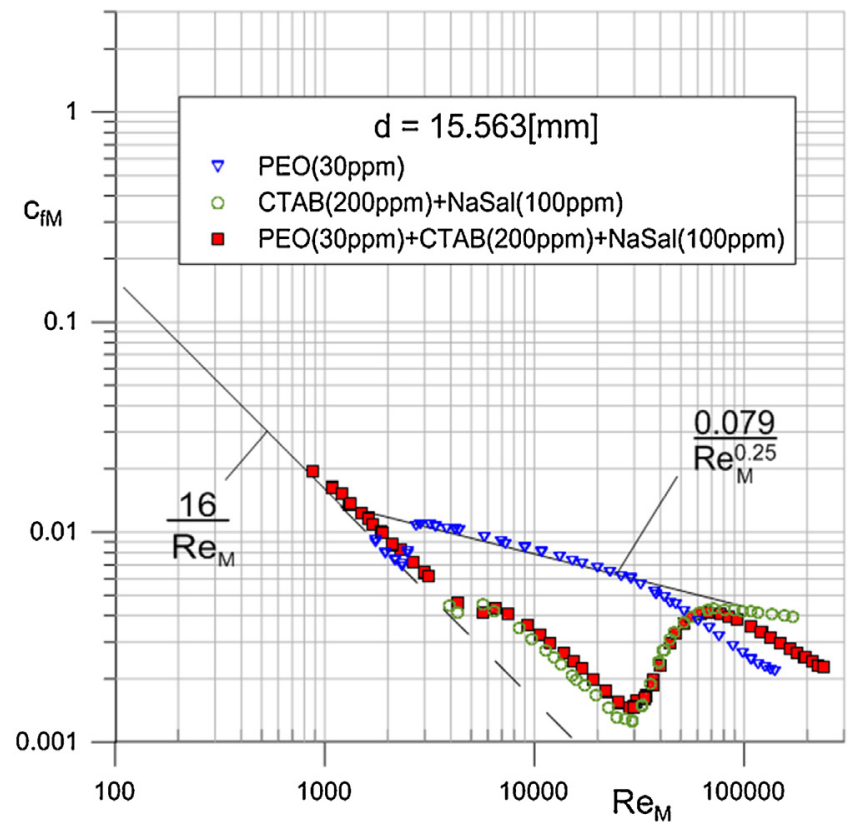

Fig. 7 - The flow resistance curves of polymer, surfactant and polymer-surfactant water solutions, defined in the system of modified dimensionless numbers (5) and (6).

for constant pipe diameter in the modified dimensionless number system (5) and (6) for the 3 analyzed types of solutions with different internal structures.

The results of the experimental data analysis indicate that polymer additives cause significant drag reduction in the turbulent range of flow. Surfactant and salt additives (micellar solution) induce the appearance of a stable transitional zone, i.e. $R e_{\mathrm{M} 1}<R e_{\mathrm{M}}<R e_{\mathrm{M} 2}$, in which a spectacular reduction of flow resistance is observed - usually grater in comparison with the same effect achieved with polymer additives. In this zone the loss of stability of the laminar flow increases very softly whereas the Reynolds number values grow. The relative drag reduction is the greatest within this range. After exceeding a certain second critical value of the Reynolds number $R e_{\mathrm{M} 2}$, the occurrence of an unstable transitional zone is observed. Within this range of flow, a rapid loss of drag reduction effect occurs. Beyond a certain third critical value of Reynolds number $R e_{\mathrm{M} 3}$ the fluid starts to behave like a classical rheostable non-Newtonian fluid.

The simultaneous addition of surfactant, salt and polymer causes the intensification of drag reduction effect in the transitional zone and its distinct extension in comparison with pure micellar solution flow, i.e. noticeable increase of $R e_{\mathrm{M} 2}$, and the additional appearance of abnormal drag reduction zone in the turbulent range of flow, above $\mathrm{Re}_{\mathrm{M} 3}$. The diagram of characteristic zones in the flow resistance curve of polymer-surfactant water solutions is presented in Fig. 8.

The phenomenon of stable transitional zone extension can be explained by a more stable configuration of the aggregate structure, where the micelles arrange in aggregates and the polymer macromolecules are entangled around micelles. The internal structure created with polymer-micellar aggregates arranged in accordance with the principle of the minimum resistance-aids the flow laminarization and intensifies the drag reduction effect in this range.

Similarly to the micellar solution behaviour, within the range of $R e_{\mathrm{M} 2}<R e_{\mathrm{M}}<R e_{\mathrm{M} 3}$, an unstable transitional zone occurs. In this area, a sharp increase in the flow resistance 


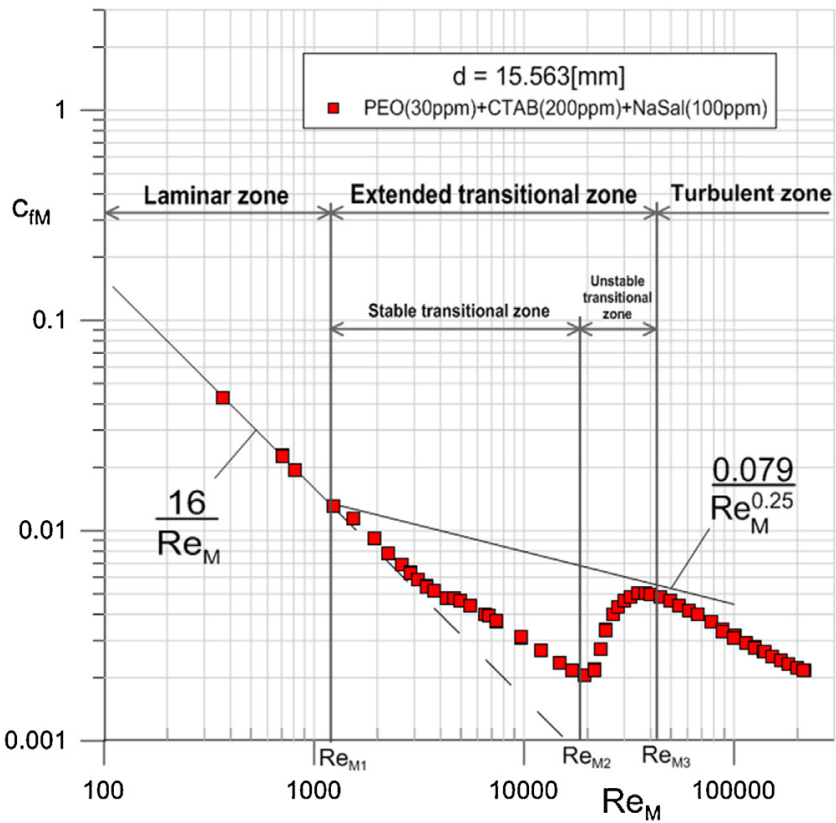

Fig. 8 - The diagram of characteristic zones in the flow resistance curve of polymer-surfactant water solutions.

is observed towards the increasing Reynolds number values. This can be caused by a partial decay of aggregates to the original forms, that is micelles and polymer macromolecules. Such a disintegration can be explained as the result of the flow rate, and consequently turbulence increase. In an unstable transitional zone of flow, equally micelles and macromolecules, acting independently, chaotically influence the solution which results in the drag reduction decrease while increasing the Reynolds number.

Going further into the range of the turbulent flow, i.e. beyond $\mathrm{Re}_{\mathrm{M} 3}$, micelles lose their orientation and no longer have a major impact on the drag reduction. A key role is played by the polymer, which did not undergo an earlier degradation and still induces the drag reduction effect. The flow resistant curve in this zone is similar to the flow resistance curve of the pure polymer solution, except the fact that the onset of its formation is shifted towards considerably higher values of $\mathrm{Re}_{\mathrm{M} 3}$.

In the drag reduction by polymer-micellar additives, the so called collapse of drag reduction is not observed. This effect occurs continuously over a wide range of Reynolds numbers. Polymer macromolecules undergo a certain mechanical degradation in the turbulent flow range. By reduction of the shear rate value, the internal structure of the polymer-micellar solution is rebuild again by a surfactant.

Once again micelles, due to the electrostatic interaction, combine with the polymer chains by wrapping them around themselves. These chains are much shorter, and aggregates formed in this manner do not have the same properties as the original ones. This results in a slight increase of flow resistance in comparison with a newly prepared solution.

The addition of the surfactant with salt to the polymer solution reduces significantly the solution's internal structure degradation.

The dominant factor in this zone is therefore the presence of the polymer and the emergence of the viscoelastic properties of the solution. It is worth noting, that the increase of polymer mass friction in a multicomponent solution increases the drag reduction effectiveness in an abnormal

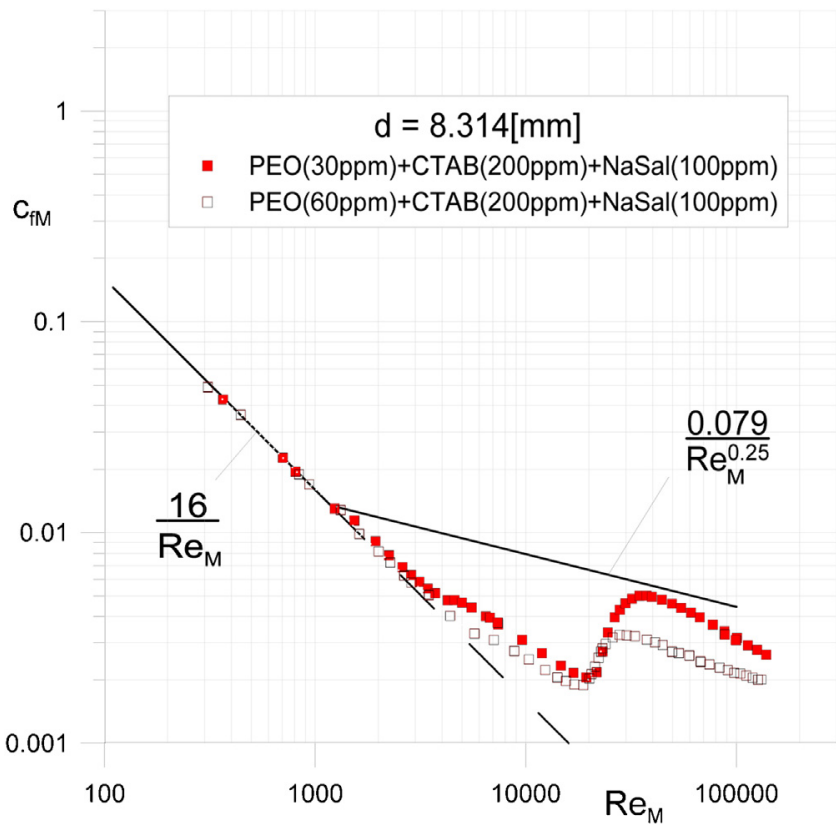

Fig. 9 - Effect of polymer concentration on flow resistance curve of polymer-micellar water solutions.

drag reduction zone in the turbulent flow range, above $\mathrm{Re}_{\mathrm{M} 3}$, and it is illustrated in Fig. 9.

The analysis of Fig. 10 (presented as an example) shows that the largest percentage drag reduction in the polymermicellar solution flow in a stable transitional zone can be obtained by the application of pipe of a greater diameter. The decrease in diameter of the pipe causes a shift in the flow resistance curve upwards, towards the higher value of $\mathrm{c}_{\mathrm{fM}}$. Therefore it facilitates the diminishing of the drag reduction effect. On the other hand - as should be emphasized, the increase in a pipe's diameter causes a rise of $R e_{\mathrm{M} 2}$ value. $\mathrm{A}$ clear extension of the stable transitional zone is observed.

The results of drag reduction measurement analysis indicate the effect of pipe diameter change on the drag reduction efficiency. The decrease in a pipe diameter value $d$ results in

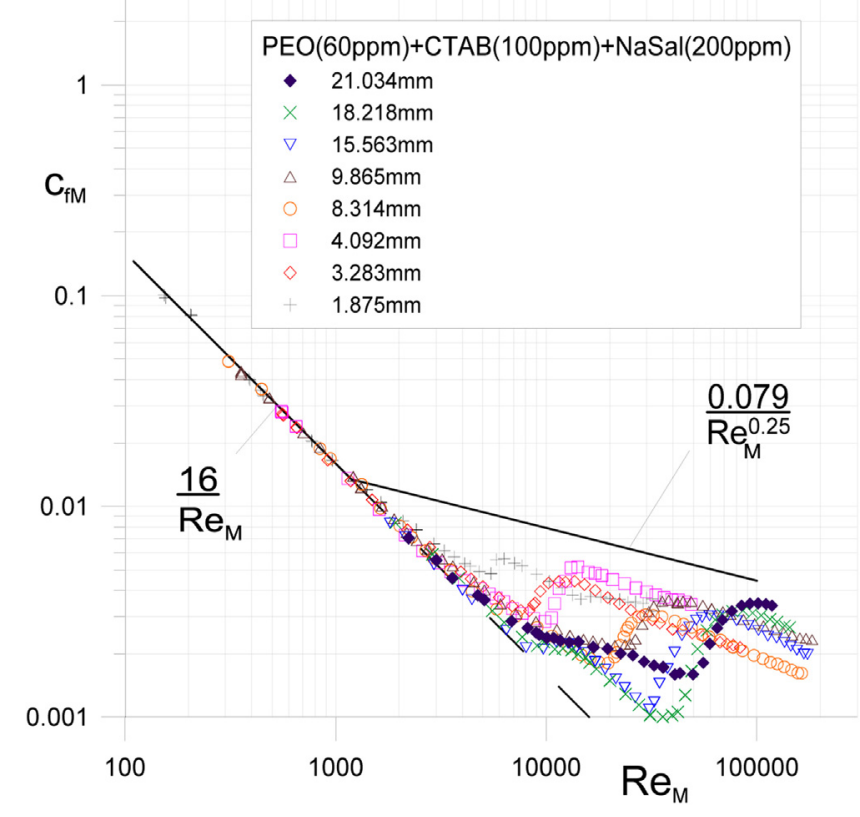

Fig. 10 - Effect of diameter on flow resistance curve of combined PEO(60 ppm) + CTAB(200 ppm) + NaSal(100 ppm). 
the increase in drag reduction effect in the third extended drag reduction zone in the turbulent range of flow - Fig. 10.

It was found that the value of flow index $n$ does not determine the final evaluation of drag reduction effect for the flow of multicomponent solution in the transitional and turbulent zones. It may happen that the fluid will be seemingly close to a Newtonian one, i.e. value of flow index $n \approx 1$, and the effects of drag reduction will be intensive (however, only in certain cases) in comparison with a fluid which reveals clearly non-Newtonian characteristics.

\section{Conclusions}

The research and the analysis of experimental data confirmed the thesis that a simultaneous addition of surfactants and high molecular polymer into the solvent causes the intensification of drag reduction effect and a significant extension of the drag reduction zones, in comparison with the drag reduction effect obtained by the application of pure polymer or pure surfactant additions. The comparative study showed that the analyzed polymer-micellar solutions combine and intensify the positive features of their purely polymer or purely micellar analogues providing more efficient drag reduction effect in a wider range of flow.

A maximum drag reduction effect in polymer-micellar solution flow is observed in a stable transitional zone, i.e. within the range of $R e_{\mathrm{M} 1}<R e_{\mathrm{M}}<R e_{\mathrm{M} 2}$. This is accompanied by the increase in the value of $R e_{\mathrm{M} 2}$. The extension of that zone is observed in comparison with a corresponding zone which occurs in a micellar solution flow. In that zone, the addition of surfactant and salt has the dominant influence on the size of the drag reduction. Polymer-micellar aggregates are responsible for the reduction of internal friction in the fluid.

In case of the unstable transitional zone $R e_{\mathrm{M} 2}<R e_{\mathrm{M}}<R e_{\mathrm{M} 3}$, a gradual disappearance of the drag reduction phenomenon is observed. Instead of the drag reduction collapse, typical for micellar solutions, the existence of the third significantly extended drag reduction zone in the turbulent range of flow is observed. The dominant factor in this zone is a high molecular weight polymer additive.

In the whole range of the Reynolds number $R e_{\mathrm{M} 1}>1200$, the diameter effect occurs. It is consists about a percentage increase in the drag reduction along with the decrease in a pipe's diameter. However, it was found that increase in a pipe's diameter causes the growth of $\mathrm{Re}_{\mathrm{M} 2}$ value. A clear extension of the stable transitional zone is observed.

The increase in the mass fraction of a polymer in analyzed multicomponent solutions intensifies the drag reduction effect in the turbulent range of flow. The addition of multicomponent substance polymer + surfactant + salt increases the solution's viscosity and the flow resistance in the laminar range of flow in comparison with the flow resistance of a pure solvent.

Simultaneous addition of polymer and surfactant with salt, in comparison with the pure polymer solution, significantly reduces the degradation of the internal structure of solution stabilizing the drag reduction effect.

\section{References}

Borostow, W., 2008. Drag reduction in flow: review of applications, mechanism and prediction. J. Ind. Eng. Chem. 14 (July), 409-416.
DaRocha, C.M., Patruyo, L.G., Ramirez, N.E., Müller, A.J., Sáez, A.E., 1999. Porous media flow of poly(ethylene oxide)/sodium dodecyl sulfate mixtures. Polym. Bull. 42, 109-116.

Dujmovich, T., Gallegos, A., 2005. Drag reducers improve throughput, cut costs. Offshore 65 (12), 1-4.

Figueredo, R.C.R., Sabadini, E., 2003. Firefighting foam stability: the effect of the drag reducer poly(ethylene) oxide. Colloids Surf. A 215 (1-3), 77-86.

Hadri, F., Besq, A., Guillou, S., Makhloufi, R., 2011. Temperature and concentration influence on drag reduction of very low concentrated CTAC/NaSal aqueous solution in turbulent pipe flow. J. Non-Newton. Fluid Mech. 166, 326-331.

Hou, Z., Li, Z., Wang, H., 1999. Interaction between poly(ethylene oxide) and sodium dodecyl sulfonate as studied by surface tension, conductivity, viscosity, electron spin resonance and nuclear magnetic resonance. Colloid Polym. Sci. 277, 1011-1018.

Kim, N.J., Lee, J.Y., Yoon, S.M., Kim, C.M., Hur, B.K., 2000. Drag reduction rates and degradation effects in synthetic polymer solution with surfactant additives. J. Ind. Eng. Chem. 6 (6), 412-418.

Kim, C.A., Jo, D.S., Choi, H.J., Kim, C.B., Jhon, M.S., 2001. A high-precision rotating disk apparatus for drag reduction characterization. Polym. Test. 20, 43-48.

Kim, J.T., Kim, C.A., Zhang, K., Jang, C.H., Choi, H.J., 2011. Effect of polymer-surfactant interaction on its turbulent drag reduction. Colloids Surf. A: Physicochem. Eng. Asp. 391 (1-3), 125-129.

Malcher, T., Gzyl-Malcher, B., 2012. Influence of polymer-surfactant aggregates on fluid flow. Bioelectrochemistry 87 (October), 42-49.

Matras, Z., 1984. Przepływ cieczu Tomsa w przewodach kołowych. Politech. Krak. Monogr. 29.

Matras, Z., Malcher, T., Gzyl-Malcher, B., 2008. The influence of polymer-surfactant aggregates on drag reduction. Thin Solids Films 516, 8848-8851.

Mohsenipour, A.A., Pal, R., 2013. Drag reduction in turbulent pipeline flow of mixed nonionic polymer and cationic surfactant systems. Can. J. Chem. Eng. 91 (January (1)), 190-201.

Mohsenipour, A.A., Pal, R., 2013a. The role of surfactants in mechanical degradation of drag-reducing polymers. Ind. Eng Chem. Res. 52 (3), 1291-1302.

Mohsenipour, A.A., Pal, R., 2013b. Synergistic effects of anionic surfactant and nonionic polymer additives on drag reduction. Chem. Eng. Commun. 200 (7), 935-958.

Mohsenipour, A.A., Pal, R., Prajapati, K., 2013. Effect of cationic surfactant addition on the drag reduction behaviour of anionic polymer solutions. Can. J. Chem. Eng. 91 (January (1)), 181-189.

Motier, J.F., Chou, L.C., Kommareddi, N.S., 1996. Commercial drag reduction: past, present, and future. In: Proceedings of the ASME Fluids Engineering Division Summer Meeting, San Diego, CA, USA.

Shu-Peng, C., 2012. Drag reduction of a cationic surfactant solution and its shear stress relaxation. J. Hydrodyn. 24 (2), 202-206.

Suksamranchit, S., Sirivat, A., Jamieson, A.M., 2006. Polymer-surfactant complex formation and its effect on turbulent wall shear stress. J. Colloid Interface Sci. 294 (February (1)), 212-221.

Tamano, S., Ito, M., Kato, K., Yokota, K., 2010. Turbulent drag reduction in nonionic surfactant solutions. Phys. Fluids 22 (5), 055102-1-055102-12.

Wang, Y., Yu, B., Zakin, J.L., Shi, H., 2011. Review on drag reduction and its heat transfer by additives. Adv. Mech. Eng. 10, 17.

White, C.M., Mungal, M.G., 2008. Mechanics and predictions of turbulent drag reduction with polymer additives. Annu. Rev. Fluid Mech. 40, 235-256. 